\title{
Polymorphism of Matrix Metalloproteinase 9 Gene (rs17576) in Nickel-Exposed Children of the Far North
}

\author{
Mazunina A.A. ${ }^{1, *}$ Dolgikh O.V. ${ }^{1}$ Zaitseva N.V. $^{2}$ \\ ${ }^{1}$ Department of immunobiological diagnostic methods Federal Scientific Research Center for Medical and \\ Preventive Health Risk Management Technologies, Perm, Russia \\ ${ }^{2}$ Federal Scientific Research Center for Medical and Preventive Health Risk Management Technologies, Perm, Russia \\ *Corresponding author. Email: alena-osa@.ru
}

\begin{abstract}
Man-made changes in the environment lead to an increase in the risk to public health. The greatest danger, in the opinion of ecologists, biologists and physicians, is technospheric pollution with heavy metals, including nickel. Nickel intoxication is accompanied by mutagenic, carcinogenic, cardiotoxic effects; it has hematotropic and immunotropic effects. The article purpose is to study the genetic status of children living in the Arctic and exposed to nickel. A survey of 136 children 3-12 years old was carried out. The observation group included 82 children with excess nickel in their blood. The comparison group included 54 children whose blood nickel content did not exceed the reference level. Genetic analysis of the frequency of polymorphism of the matrix metalloproteinase gene MMP9 (Gln279Arg, rs17576) was carried out by realtime PCR with further allelic discrimination. According to the results of studies of the health status of the child population, the presence of early changes in the immune system was revealed, which are manifested in the hyperproduction of class A immunoglobulins in children of the observation group $(\mathrm{p}<0.05)$. It was found that the occurrence of the minor G allele of the MMP9 gene (rs17576) in the observation group is $45 \%$, which is 1.7 times higher than that in the comparison group $(p<0.05)$. The detected excess frequency of the G allele of the MMP9 gene (rs17576) in children of the Far North living in a technogenic "nickel" province is associated with insufficient processes of destruction of the extracellular matrix, which creates a danger of the emergence and development of proliferative and oncological conditions.
\end{abstract}

Keywords: genetic polymorphism, MMP9 gene (rs17576), risk, nickel

\section{INTRODUCTION}

Currently, in industrially developed countries, despite all the measures taken to minimize the harmful effect, the impact on health of exogenous chemical factors, in particular heavy metals, is increasing [1].

One of the top-priority technogenic haptenes possessing the properties of an allergen and a carcinogen is such a heavy metal as nickel [1]. The carcinogenic properties of nickel are caused by lipid peroxidation, impaired fat and carbohydrate metabolism, and changes in the concentration of biologically active mediators in blood serum [4]. With an excess content of nickel in the body, the risk of developing neoplasms in the lungs, kidneys, and skin increases [2].

Purpose of the study: to study the features of the genetic status of children of the Far North exposed to nickel.

\section{MATERIALS AND METHODS}

The territory of the Arctic was selected for the study. The object of the study was 136 children 3-12 years old living in artificially created conditions of various exposure to nickel. The observation group consisted of 82 children $3-10$ years old (46 boys, 36 girls), whose blood nickel content was above the reference range; the comparison group included 54 children 3-12 years old (25 boys, 29 girls), whose blood nickel content did not exceed the reference level. All children were tested for nickel content by mass spectrometry on an Agilent $7500 \mathrm{cx}$ mass spectrometer (USA).

Determination of class A immunoglobulins in blood serum was performed by radial immunodiffusion (according to Mancini method).

The distribution of the Gln279Arg polymorphism of the MMP9 gene (rs17576) was investigated by the SNP method using commercial test systems of the Syntol company in DNA samples isolated from the buccal epithelium using the Sorb-AM kit (AmpliPrime, Russia), on the CFX96 ${ }^{\mathrm{TM}}$ Real-Time System (Bio-Rad, USA). To determine the human genotype, we used the method of allelic discrimination, when the differences between the heterozygotes and homozygotes of the normal and minor variants were established by the differences in the course of amplification reactions of the corresponding primers. 
The calculation of the distribution of the frequencies of genotypes and alleles in the groups was carried out using Microsoft ${ }^{\circledR}$ Office Excel 2003 spreadsheet. The differences between the groups were considered significant at $\mathrm{p}<0.05$. Statistical methods were used to describe the frequencies of genotypes based on the HardyWeinberg equilibrium. Also, the results of the study were processed using the Statistica 6.0 software. The arithmetic mean $(\mathrm{M})$ and the error of the mean $(\mathrm{m})$ were calculated. We used the Student's t-test to compare groups by quantitative criteria. The differences were considered significant at a significance level of $p<0.05$.

\section{RESULTS}

The chemical analysis of blood showed that the observed group of children had a significantly increased content of nickel in the blood relative to the reference level ( 5 times) and the comparison group by 7.5 times $(\mathrm{p}<0.05)$. The immunological analysis of the blood made it possible to establish that the level of immunoglobulin A did not go beyond the reference range, but in the intergroup comparison there was a significant overproduction in the observation group (1.2 times) relative to the comparison group (p < 0.05) (Table 1).

Table 1 Markers of exposition and effect in children of the nickel province of the zapolaria

\begin{tabular}{|c|c|c|c|c|}
\hline Indicator & Reference interval & Observation group $(\mathrm{n}=82)$ & Comparison group $(\mathrm{n}=54)$ & $\mathrm{p}$ \\
\hline Nickel $\left[\mu \mathrm{g} / \mathrm{vm}^{3}\right]$ & $0.0018-0.0027$ & $0.0090 \pm 0.0013$ & $0.0012 \pm 0.0002$ & 0.00 \\
\hline Ig A $\left[\mathrm{g} / \mathrm{dm}^{3}\right]$ & $1.17-2.20$ & $1.42 \pm 0.12$ & $1.19 \pm 0.11$ & 0.01 \\
\hline
\end{tabular}

The significant increase in the level of immunoglobulin class $\mathrm{A}$ is probably associated with the processes of compensation and adaptation of the immune system to the combined conditions of the North and exogenous chemical contamination with nickel.

The evaluation of the distribution of genotype frequencies for their compliance with the Hardy-Weinberg population equilibrium in the observation and comparison groups did not reveal any deviations in the samples

Table 2 Results of genotyping of the studied MMP9 gene
( $p>0.05$ ); therefore, the analysis of genetic differences was carried out using a multiplicative model of inheritance.

According to the analysis of the Gln279Arg polymorphism of the MMP9 (rs17576) gene, a significant $(\mathrm{p}<0.05)$ difference in allele frequencies is observed in children with a high nickel content in the blood. The occurrence of the $G$ allele in the observation group was 1.7 times higher than in the comparison group (Table 2).

\begin{tabular}{|c|c|c|c|c|c|c|}
\hline \multirow{2}{*}{ Gene } & \multirow{2}{*}{$\begin{array}{l}\text { Genotype/ } \\
\text { allele }\end{array}$} & \multicolumn{2}{|c|}{ Relative frequency [\%] } & \multirow{2}{*}{$\mathrm{p}$} & \multicolumn{2}{|c|}{ OR } \\
\hline & & Observation group $(\mathrm{n}=82)$ & Comparison group $(\mathrm{n}=54)$ & & signif. & $95 \% \mathrm{CI}$ \\
\hline \multirow{5}{*}{$\begin{array}{c}M M P 9 \\
(\mathrm{G} \ln 279 \mathrm{Arg}, \\
\mathrm{rs} 17576)\end{array}$} & $\mathrm{A} / \mathrm{A}$ & 34 & 58 & \multirow{3}{*}{-} & \multirow{3}{*}{-} & \multirow{3}{*}{-} \\
\hline & $\mathrm{A} / \mathrm{G}$ & 43 & 31 & & & \\
\hline & $\mathrm{G} / \mathrm{G}$ & 23 & 11 & & & \\
\hline & $\mathrm{A}$ & 55 & 73 & \multirow{2}{*}{0.003} & 0.46 & $0.27-0.78$ \\
\hline & $\mathrm{G}$ & 45 & 27 & & 2.19 & $1.32-3.58$ \\
\hline
\end{tabular}

\section{DISCUSSION}

The family of matrix metaloproteinases (MMPs) consists of enzymes capable of degrading almost all components of the extracellular substance of connective tissue. They perform an important function in many physiological and pathological processes. Metalloproteinases are secreted by many cells, including fibrocytes, epithelial and oncotransformed cells, phagocytes, leukocytes, and vascular myocytes [3]. Insufficiency of the program of enzymatic cleavage of the extracellular and extracellular matrix leads to a decrease in the control of proliferative processes, and the adjuvant role of hexavalent nickel as a simulator of LPO-mediated events leads to mitochondria-mediated stimulation of accelerated mitosis.
Thus, a study on the example of 744 patients diagnosed with lung cancer showed that the G/G rs17576 genotype was significantly associated with a higher risk of lung cancer and metastasis $(\mathrm{OR}=1.79,95 \% \mathrm{CI}=1.03$ 3.08) compared to with genotype A/A [5].

In the future, it is required to conduct more large-scale and representative studies, including taking into account the combined conditions of the Far North [6].

\section{CONCLUSION}

The matrix metalloproteinase gene MMP9, in the case of its polymorphism, plays a central role in the processes of tumor transformation, metastasis, and the conditions of 
excessive contamination with nickel as a carcinogen create additional risks of triggering proliferative scenarios. The minor allele $G$ of the MMP9 gene (rs17576) can be additively combined with the extreme climatic conditions of the Far North and the carcinogenic aggressiveness of exogenous hexavalent nickel, forming the risk of developing oncological conditions in the future.

\section{REFERENCES}

[1] N.N. Bushuev, Heavy metals in industrial production and their impact on human health, Health - the basis of human potential: probl. and solute. 6(1) (2011) 115.

[2] N.B. Ivanenko, A.A. Ivanenko, E.B. Nosova, N.D. Soloviev, Determination of beryllium and nickel in the blood by atomic absorption method with electrothermal atomization and Zeeman modulation polarization background correction, Bull. of St. Petersburg Univer. Ser. 4. Physics. Chem. 3 (2011) 96-102.
[3] A.S. Krutova, V.N. Luchaninova, O.V. Semeshina et al., The role of matrix metalloproteinases and their inhibitors in physiopathological processes in children with kidney diseases, Pacific Med. J. 1 (2020) 11-15.

[4] O.A. Sen'kevich, Z.V. Sirotina, Yu.G. Kovalsky, N.V. Berdnikov, Toxic microelements of the fruitmaternal complex under conditions of anthropogenic load, Far Eastern Med. J. 2 (2008) 61-64.

[5] Z. Hu, X. Huo, D. Lu et al., Functional polymorphisms of matrix metalloproteinase-9 are associated with risk of occurrence and metastasis of lung cancer, Clin. Cancer Res. 11(15) (1 Aug. 2005) 5433-5439.

[6] H. Zhou, X. Xuming Zhu, Association between matrix-metalloproteinase polymorphisms and prostate cancer risk: a meta-analysis and systematic review, Cancer Manag. and Res. 10 (2018) 5247-5259. 